${ }^{1}$ SOSTRES, Josep Maria. Opiniones sobre arquitectura. Murcia: Colegio Murcia, 1983, p. 7 .

${ }^{2}$ FLORES, Carlos. Arquitectura Española Contemporánea. Madrid: Ed. Aguilar, vol. 1 y 2, 1961

${ }^{3}$ BOHIGAS, Oriol. "Josep Maria Sostres y José Antonio Coderch". En: Entusiasmos compartidos y batallas sin cuarte. " SOSTRES, Josep Maria. "Los monumentos de tochana". En
ARMESTO, Antonio; MARTÍ, Carles (ed.). Sostres: Arquitectearquitecto. Barcelona: Ministerio de Fomento de España y Collegi

${ }^{5}$ GARCÍA-ESCUDERO, Daniel; BARDÍ i MILÀ, Berta (compiladores). [Antonio Armesto Aira; Jorge Torres Cuenco; Rafael Diez Barreñada; Orsina Simona Pierini; Raúl Castellanos; Débora Domingo; Josep Quetglas; Felix Solaguren-Beascoa; Buenos Aires, 2015.

${ }^{6}$ Junto a las publicaciones, también es de indudable valor la entrevista que concedió a Josep Quetglas. Véase: QUETGLAS,

72C Construcción de la Ciudad, n. 4, agosto 1975. [Número monográfico dedicado a Josep Maria Sostres].

${ }^{8}$ ARMESTO, Antonio; MARTÍ, Carles (ed.) [Josep Quetglas; Xavier Monteys; Simona Pierini; Michele Bonino; Carles Mart'; Antonio Armesto (autores)]. Sostres: Arquitecte-arquitecto. Barcelona: Ministerio de Fomento de España y Coll-legi d'Arquitectes de Catalunya, 1999. BONINO, Michele. Josep

9 LAHUERTA, J.J.; Muro, C.; PIZZA, A.; QUETGLAS, J. José Maria Sostres: Ciudad Diagonal. Barcelona: Ed. Galería C.R.C. 198

MURO, Carlos; QUETGLAS, Josep. Josep M. Sostres: Cinc assaigs d'arquitectura. [Barcelona]: Col-legi d'Arquitectes

Catalunya, Demarcació de Girona i Tarragona, 1990.

${ }^{11}$ SOSTRES, Josep Maria. Opiniones de arquitectura, op. cit., p. 51-57 ("Cronologia gaudinista en tres tiempos", 1953). ${ }^{12}$ TUSQUETS, Oscar. "Responso por la escalera". En: Todo es a, 1998, p. 83-86.

${ }^{13}$ BOHIGAS, Oriol. op. cit., p. 46.

${ }_{14}^{14}$ Desde la Escuela de Arquitectura de Madrid son prácticamente inexistentes los comentarios o análisis sobre la figura de Sostres. el III tomo de Historia de la arquitectura contemporánea españo (Madrid: Molly Editorial, 1997) -realizado en colaboración con María Teresa Muñoz-. Durante las largas conversaciones co María Teresa Muñoz que copan el libro, Fullaondo lamenta no haberle conocido, y aunque admite el casi absoluto dedicarle elogiosas palabras.

${ }^{15}$ AZÚA, Félix de. Lecturas compulsivas: una invitación. Barcelona: Anagrama, colección argumentos, 1998.

${ }^{16}$ SOSTRES, Josep Maria. Opiniones de arquitectura, op. cit. p. 275

Ibid., p. 64-65

${ }_{18}$ Ibid., p. 65-66.

9 "Una de las maneras más efectivas de aprender es por Este tipo de solo aprender contenidos, sino también actitudes. Este tipo de imitacion se adquiere gracias a unas neuronas specificas, llamadas neuronas espejo, que nos permiten eproducir dentro de nosotros mismos todo aquello que vemos hacer en los demás, y también sus emociones, lo cual nos permite deducir las intenciones." BUENO, David. "Una visio neurocientif Arquitectura. Barcelona: Iniciativa Digital UPC, 2015, p. 12

${ }^{20}$ SOSTRES, Josep Maria. Opiniones de arquitectura, op. cit., p

${ }^{21}$ MARTÍ ARÍS, Carles. "El análisis de los ejemplos de la arquitectura como base de la enseñanza de proyectos". [Texto inédito escrito con motivo del Seminario permanente sobre la enseñanza de proyectos que tuvo lugar en la Escuela de Arquitectura de Barcelona, el 3 de febrero de 1982.

${ }^{22}$ MONEO, Rafael. "Acerca de Palladio: una lección en Vicenza, 500 años después". Arquitectura Viva, 2009, núm. 122. $23 \mathrm{lbid}$.

ABSTRACT

El pasado 15 de mayo de 2015 se cumplía el centenario del nacimiento de Josep Maria Sostres. Fue un profesor de historia del arte y la arquitectura, un crítico informado y lúcido, un arquitecto abnegado y cuidadoso. Sus proyectos partían de unos depurados principios de clara vocación didáctica. A partir de esos principios, Sostres hablaba de sus obras con distancia y precisión, convirtiéndolas en herramientas de estudio y aprendizaje, en ejemplos de un conocimiento acumulativo y aprendizaje, en ejemplos de un conocimiento acumulativo
fruto de la tradición moderna. Con motivo de la efeméride, se acaba de publicar el libro Josep Maria Sostres: Centenario, unos acaba de publicar el libro Josep Maria Sostres: Centenario, unos estudios críticos en torno a su figura, pensamiento y obra. Desde de un conocimiento más completo de un arquitecto que hoy en día continúa siendo marginal. Un arquitecto que frente a discursos dominantes de la transversalidad, la creatividad y la innovación, reivindicaba que la única especialidad original de arquitecto es la Arquitectura.

PALABRAS CLAVE: Josep Maria Sostres, centenario, proyectos arquitectónicos, aprendizaje.

DANIEL GARCÍA-ESCUDERO es Doctor arquitecto y Profesor Lector en el Departamento de Projectes Arquitectònics de la UPC ETSAB.

BERTA BARDÍ I MILÀ es Doctora arquitecta y Profesora Asociada en el Departamento de Projectes Arquitectònics de la UPC ETSAV.

\title{
La crítica arquitectónica y la imagen del arquitecto
}

\section{Rafael Gómez-Moriana}

Recibido 2015.06.14 ::.: Aceptado 2015.06.19 DOI: 10.5821/palimpsesto. 13.4638

a imagen importa más que nunca. En la sociedad en la que vivimos, nos guste o no, - la forma cuenta más que el contenido. En arquitectura, esto puede tener varias interpretaciones: que la forma de un edificio mismo importe más que su función, pero también que la 'representación' de una obra en medios de comunicación importe más que su fisicalidad; porque siempre será visto por un público mucho más amplio a través de fotografías en medios de comunicación que visitado o palpado 'in situ'. El medio es el mensaje, como dijo Marshall McLuhan al principio de los 60. Hoy en día este hecho es aún más evidente. Dicho esto, está claro que también importa la obra física en la arquitectura, sobre todo para los usuarios, y los que están pagando por ella. Pero todos sabemos que la arquitectura, especialmente en casos de obra pública, siempre tiene una 'utilidad' adicional al programa de uso, y esa utilidad es crear imagen para alguien. Vivimos en una sociedad cada vez más mediatizada, y cada vez más competitiva, lo que hace que se compita cada vez más en el campo de los medios y las imágenes. Guste o no, es así.

Me empecé a interesar en escribir sobre arquitectura al darme cuenta un día de que ver un articulo mío publicado en una revista me daba un subidón muy parecido al de ver una obra propia completada, con la diferencia que me costaba menos tiempo, y no requería para ello de un seguro de responsabilidad civil. Por contra, también son bastante menores los honorarios que se perciben por escribir.

La imagen es muy importante hoy en día, pero la crítica no consiste en construir imagen. La imagen es solamente una consecuencia de la crítica, un subproducto. La tarea principal de la crítica es poner a día continuamente el canon arquitectónico. No todo lo que se diseña o se construye puede ser considerado emblemático, o un ejemplo a seguir. No todo puede incluirse en los libros de historia de la arquitectura. Hace falta seleccionar, filtrar. La crítica es ese 'primer filtro'. Sirve, en un primer instante, para separar el trigo de la paja; o lo que es lo mismo, 'la arquitectura' de 'la construcción'. Lo bueno de lo feo o lo malo.

Por eso, una vez seleccionada una obra para ser publicada, ya no importa mucho si la crítica es positiva o negativa. El mero hecho de haber sido publicada ya le otorga cierto prestigio a una obra. Como dijo Oscar Wilde: "Hay solamente una cosa en el mundo peor a que hablen mal de ti, y es que no hablen de ti". O como dijo Philip Johnson: "Di lo que quieras sobre mí, pero por favor, escribe mi nombre correctamente".

Hace poco, el arquitecto Patrick Schumacher (socio en el estudio de Zaha Hadid) dijo en facebook que los críticos deben 'explicar' lo que hacen los arquitectos en lugar de juzgar. Que su rol es de actuar como intermediario para transmitir un mensaje desde el arquitecto al público. Yo me opongo rotundamente a este papel. La crítica es una interpretación o una lectura de una obra. A lo mejor, una lectura que ni se le ocurrió al arquitecto.

Hay una diferencia muy importante entre la nota o memoria explicativa de proyecto que redacta un arquitecto en la que describe sus intenciones, o la nota de prensa escrita por una agencia de comunicación, y un texto escrito por un 'crítico', que describe, opina, interpreta, y sí, juzga. La memoria y la nota de prensa no son 'crítica' precisamente porque 'explican' intenciones. La crítica tiene que ser independiente, autónoma. Sin una evaluación independiente, una obra de arquitectura jamás podrá ser aceptada en la colección de obras canónicas; es decir, en los libros de historia.

Desafortunadamente, muchos supuestos 'críticos' no entienden este principio, y con ello efectivamente, crítica está sufriendo una falta de credibilidad. Muchas




revistas ya no incluyen textos de crítica, sino memorias explicativas o textos basados directamente en notas de prensa. La crítica independiente cuesta tiempo y dinero, porque se hace desinteresadamente, al menos en teoría. Por desgracia, como muchas revistas - sean físicas o digitales - tienen dificultades para llegar a fin de mes, optan por la vía fácil.

Por otra parte, el hecho de cómo ciertos arquitectos se han convertido en súper-estrellas, es algo que hace que la crítica a sus obras sea vista como algo sospechoso. "Qué le pasa a este crítico? A todo el mundo le gusta esta obra menos a él!".

Otro problema es la fotografía arquitectónica: es tan buena y tan seductora, que resulta difícil ser crítico su lado. Todo es siempre fantástico en la fotografía arquitectónica: el cielo es azul, la gente guapa, y los edificios chulísimos.

En mis experiencias con algunas revistas me he encontrado con casos en que no han querido publicar un texto demasiado crítico. Tienen miedo a ofender al arquitecto, que a lo mejor les ha ofrecido fotografías gratis y promete comprar ' $x$ ' números de la revista para regalar a sus clientes, si el texto es favorable, claro. Por eso creo que está teniendo mucho éxito Mark Magazine una revista Holandesa internacional cuyos editores dan mucha libertad a los escritores para opinar, cosa que, como uno de los corresponsales de esta revista, agradezco mucho.

También es cierto que la decisión, por parte de un editor, de incluir o no una obra determinada en su revista se suele hacer basándose casi siempre en la calidad de la fotografía, y no tanto en la calidad del texto. La buena fotografía es imprescindible para las revistas, que muchos ojeamos por encima viendo únicamente las imágenes al decidir si comprarla o no. Por tanto, el texto suele ser secundario a la imagen. No debería ser así, creo yo, pero en fin. Es como funcionan la mayoría de revistas.

En el número 50 de Mark, traté de 'revisitar' 5 obras españolas que en su día ya fueron publicados en esta misma revista. Escribí un artículo que pone la mirada de nuevo sobre algunas obras emblemáticas años después de la finalización de la construcción, estando ya en uso. La idea la propuse yo a los editores, porque estaba harto de escribir siempre sobre obras cuando aún tenían olor a pintura. Cuando ves un edificio recién acabado, aún sin vida, no se puede evaluar su rendimiento y su funcionalidad, criterios que también son muy importantes, en mi opinión. En la teoría, los edificios suelen ser perfectos, pero en la realidad nunca lo son. Sin embargo, me interesa más la imperfección real que

La imagen es muy importante hoy en día, pero la crítica no consiste en construir imagen. La imagen es solamente una consecuencia de la crítica, un subproducto. La tarea principal de la crítica es poner al día continuamente el canon arquitectónico.

la perfección ideal. Ofrece más matices, anécdotas, y poesía para la lectura de una obra. En este artículo vimos publicadas algunas fotos muy diferentes a las que se suelen publicar en la mayoría de los casos. No son fotos que dan precisamente buena imagen al arquitecto o al político interesado en sacar provecho a una obra emblemática.

Una de las responsabilidades de la crítica es, entre otras cosas, la denuncia. Como ya sabemos los seguidores de Masters of Concrete, en la arquitectura hay algunos impostores y charlatanes, y es importante que sean desmitificados, pero siempre, creo yo, fijandose en su obra y nunca exclusivamente en su persona.

La fachada de un edificio calificado de 'ecológico' en Barcelona nos ofrece un buen ejemplo. Sus placas fotovoltaicas tienen teóricamente la función adiciona de dar sombra a sus ventanas en verano, evitando así el calentamiento solar interior y ahorrando en aire acondicionado. En invierno, en cambio, dejan pasar los rayos del sol para calentar el interior. La idea es genial. El problema es que las placas se hacen también sombra a sí mismas, por el juego formal que hace la fachada. Si las ventanas y sus viseras estuviesen todas a la misma altura, esto no ocurriría. Pero claro, estéticamente no
Somos lo que construimos, algo que conocemos muy bien en este país, y la crítica arquitectónica es también una importante tarea de análisis social. Yo, al menos veo asi mi 'responsabilidad civil'; mi lugar como ciudadano.

sería tan atractivo. Curiosamente, los arquitectos dicen haber utilizado parametricismo para 'optimizar' la exposición solar de las placas. Es evidente que en realidad, lo que han intentado optimizar es la forma estética, tal vez porque saben que la imagen importa más que el rendimiento. ¿Qué más podemos esperar de una empresa de suministro energético que necesita lavar su imagen mediante "Green-washing" y de unos arquitectos dispuestos a vender su alma?

La crítica es necesaria para mantener bajo control a los arquitectos, políticos y empresarios demasiado ambiciosos. La crítica, entendida como oposición, como sistema de control de calidad, es imprescindible en una democracia. Hay que entender, además, que la crítica arquitectónica no está dirigida a los arquitectos únicamente sino a la sociedad en su conjunto. Somos lo que construimos, algo que conocemos muy bien en este país, y la crítica arquitectónica es también una importante tarea de análisis social. Yo, al menos veo así mi 'responsabilidad civil'; mi lugar como ciudadano.

Hay países que no toleran la crítica, como bien conocemos en este país, sobre todo los que tenemos cierta edad. En Irán, por ejemplo, mi blog, criticalista.com, esta censurado. En su lugar salen unas recomendaciones oficiales para visita sitios web 'alternativos'. Nunca he mencionado Irán en ningún post, pero esto no importa. No quieren que sus ciudadanos vean que un chalado como yo pueda expresar sus opiniones con más o menos libertad. Este tipo de censura está dando mala imagen a lrán y a otros países, forzándoles a cambiar sus políticas poco a poco. La noción de 'imagen mediática' tiene también su lado positivo, me gustaría destacar.

Sitios como Archileaks son una forma de crítica alternativa y complementaria a la que hacemos los críticos. Quiero destacar que firmo siempre lo que escribo, con mi nombre real. Estoy también dispuesto a que me critiquen a mí. Nadie es perfecto. Todos hemos cometido errores; todos la hemos cagado en algún momento. Algunas veces he metido la pata, $\mathrm{y}$ he tenido que reconocer mis errores. Es menos arriesgado criticar desde el anonimato, pero en cambio es también menos creible.

Hoy en día casi todos somos críticos. Todos opinamos, todos ponemos 'likes' en facebook o estrellitas en twitter. Este hecho también está cambiando la crítica tal como la conocíamos antes, cuando un puñado de críticos tenía cierto monopolio sobre esta tarea. Son tiempos interesantes los que estamos viviendo; tiempos de cambio y de inestabilidad. Precisamente por esto hace falta más que nunca una crítica comprometida, y desinteresada. Y por qué no, también con un poco de humo

\section{ABSTRACT}

¿En qué consiste la crítica arquitectónica: en explicar o en juzgar? ¿Cual es su tarea dentro de un sistema democrático, o dentro de un star-system de ámbito global? ¿Por qué suelen tener los críticos mala leche? Este texto trata de dar respuesta a preguntas comunes sobre la crítica arquitectónica, y sobre su relevancia hoy en día (si es que aún tiene relevancia alguna en la era de los medios sociales), contrastando la crítica con otros tipos de textos que construyen la imagen del arquitecto, y con la fotografía arquitectónica que suele acompañarla.

PALABRAS CLAVE: crítica, imagen, fotografía.

RAFAEL GÓMEZ-MORIANA estudió arquitectura en la University of Waterloo (Canadá) y realizó un máster en el Berlage Institute Amsterdam. Es miembro del Comité Internacional de Críticos de Arquitectura, y 'bloguea' en criticalista.com.
Xumeu Mestre

\section{In memoriam}

\section{Jaume Prat Ortells}

Recibido 2015.06.16 … Aceptado 2015.06.18 DOI: 10.5821/palimpsesto. 13.4640

dels llocs comuns més usats pels professors dolents, o, pitjor encara, pels professors mediocres, consisteix en afirmar que l'arquitectura no es pot ensenyar.

Fals.

Per una banda hi ha tot el relatiu a la tècnica. Per l'altra, els referents. Els exemples. Les tipologies. L'esperit crític. Però res d'això funciona si no som capaços d'entendre que l'arquitectura es alguna cosa més. L'arquitectura requereix visió positiva. Requereix joc. Requereix encomanar entusiasme. Requereix vida. L'arquitectura ha de ser útil, cert. L'alegria, la ill-lusió, el sentiment positiu formen part integrant d'aquesta utilitat. Sí, projectar costa. Sí, hi ha arquitectes que pareixen amb dolor. I hi ha el maquillatge.

L'aparença és el vestit social. La mateixa paraula persona prové de màscara. No ens veuen, ni tan sols ens veiem, com som. Ens veiem com ens projectem. Igual que l'arquitectura. Si projectem façanes per als nostres edificis hem de projectar-nos-en una per nosaltres mateixos

Es pateix de portes endins.

La societat ni ens deu res ni necessita saber d'aquest patiment com no sigui per les ganes d'algú curiós a mira més enllà i entrar a la cuina dels projectes.

La societat no necessita patir. I de ben segur que la societat no necessita patir un projecte.

El mateix és vàlid per a l'escola.

L'escola és el temps de la formació. Formació positiva. Gaudi. L'escola transmet, o hauria de transmetre, valors. Massa sovint sortim al carrer i no ens agraden els edificis que hi veiem. Potser és així perquè no s'ha sabut transmetre això des de l'escola.

En Xumeu Mestre sí.

En Xumeu representa la bona ensenyança de l'arquitectura. El recordo fent-nos classes mentre cuinav una paella. De resultes d'aquell dia sempre que m'he vist amb la necessitat de congelar una sípia ho he fet amb la sípia bruta, sense netejar. Manté millor el gust. En Xumeu representa classes interrompudes abruptament per a improvisar altres classes que no se't obliden mai més. En Xumeu ens va ensenyar a mirar en Miquel Àngel com l'arquitecte modern que és. Ens va ensenyar que hi ha quadres que et posis on et posis sempre et miren als ulls. A alguns això els posa nerviosos. Ell reia. I ens feia riure.

Ens va ensenyar que el Vaticà és un parc aquàtic. Ens va ensenyar que en Pep Llinàs no juga als daus. Que els escrits d'arquitectura poden tenir, o han de tenir, dimensió literària.

En Xumeu divertia.

Divertia en el sentit literal del terme: di-vertia. Diversificava mirades. Multiplicava punts de vista. Et feia arribar més

En Xumeu és l'exemple de que l'arquitectura sí es pot ensenyar. En Xumeu mostrava dia a dia com es pot viure, com es pot respirar arquitectura facis el que facis. A costa d'un cert caos, de vegades. Bé, potser fins i tot una mica més que un cert caos. En Xumeu és, per tot això, un exemple.

En Xumeu és algú sobre el que s'ha de parlar en present perquè el que volia transmetre és i serà plenament vigent. No crec que es pugui dir res millor sobre ell que això. Gràcies, Xumeu. Gràcies per encomanar-nos tot això. Gràcies per ser-hi.

JAUME PRAT ORTELLS es arquitecto por la ETSAB y editor asociado de la colección Scalae e-books. Recientemente ha sido ganador, junto a Isaki Lacuesta y Jelena Prokopljevic, del concurso para el Pabellón de Catalunya en la Bienal de Arquitectura de Venecia 2016. 